\title{
Number of Primary Tumors in this Location
}

National Cancer Institute

\section{Source}

National Cancer Institute. Number of Primary Tumors in this Location. NCI Thesaurus.

Code C158696.

A directive to specify the number of primary tumors in the specified location. 